\title{
Effects of 10 Cigarette Smoke Condensates on Primary Human Airway Epithelial Cells by Comparative Gene and Cytokine Expression Studies
}

\author{
Gavin Pickett, ${ }^{* 1}$ JeanClare Seagrave, $\dagger^{\dagger, 2}$ Susan Boggs, $\ddagger$ Gregory Polzin,§ Patricia Richter, $₫$ and Yohannes Tesfaigzi $\dagger$

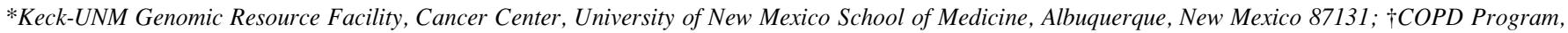 \\ Lovelace Respiratory Research Institute, Albuquerque, New Mexico 87108; $\$$ Sandia National Laboratory, Albuquerque, New Mexico 87185; §Division of

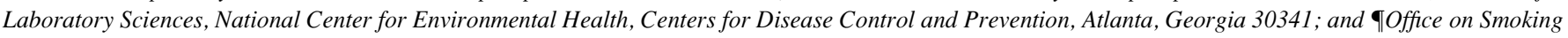 \\ and Health, National Center for Chronic Disease Prevention and Health Promotion, Center for Diseases Control and Prevention, Atlanta Georgia, 30341 \\ ${ }^{1}$ These authors contributed equally to this study. \\ ${ }^{2}$ To whom correspondence should be addressed at Lovelace Respiratory Research Institute, 2425 Ridgecrest Dr. SE, Albuquerque, NM 87108. \\ Fax: (505) 348-8567. E-mail: jseagrav@lrri.org.
}

Received October 19, 2009; accepted December 7, 2009

Cigarettes vary in tobacco blend, filter ventilation, additives, and other physical and chemical properties, but little is known regarding potential differences in toxicity to a smoker's airway epithelia. We compared changes in gene expression and cytokine production in primary normal human bronchial epithelial cells following treatment for $18 \mathrm{~h}$ with cigarette smoke condensates (CSCs) prepared from five commercial and four research cigarettes, at doses of $\sim 4$ $\mu \mathrm{g} / \mathrm{ml}$ nicotine. Nine of the CSCs were produced under a standard International Organization for Standardization smoking machine regimen and one was produced by a more intense smoking machine regimen. Isolated messenger RNA (mRNA) was analyzed by microarray hybridization, and media was analyzed for secreted cytokines and chemokines. Twenty-one genes were differentially expressed by at least 9 of the 10 CSCs by more than twofold, including genes encoding detoxifying and antioxidant proteins. Cytochrome P450, family 1, subfamily A, polypeptide 1 (CYP1A1) and $\mathrm{NAD}(\mathrm{P}) \mathrm{H}$ dehydrogenase, quinone 1 (NQO-1) were selected for validation with quantitative real-time PCR (qRT-PCR) and Western blot analyses. NQO-1 expression determined with microarrays, qRT-PCR, and Western blotting differed among the CSC types, with good correlation among the different assays. CYP1A1 mRNA levels varied substantially, but there was little correlation with the protein levels. For each CSC, the three most induced and three most repressed genes were identified. These genes may be useful as markers of exposure to that particular cigarette type. Furthermore, differences in interleukin-8 secretion were observed. These studies lay the foundation for future investigations to analyze differences in the responses of in vivo systems to tobacco products marketed with claims of reduced exposure or reduced harm.

Key Words: cigarette smoke condensates; primary human lung epithelial cells; gene expression; toxicity; cytokine.

The adverse health effects from cigarette smoking account for 440,000 deaths in the United States each year. Smoking harms nearly every organ in the body, causing many diseases and reducing the health of smokers in general (Das, 2003; Department of Health and Human Services [U.S.], 2004). Cigarette smoke contains more than 4000 chemicals, including more than 60 carcinogens (Chen et al., 2008). Comparisons of different cigarette types have clearly demonstrated differences in the chemical composition of the smoke as a function of additives (Baker et al., 2004a), paper type (Baker et al., 2004b), tobacco processing (Martin et al., 2003), and other manufacturer-specific features (Harris, 2001).

Some studies have suggested that reduction of nicotine, the addictive component of cigarette smoke, may permit a gradual reduction of smoking (Djordjevic et al., 2000). However, there is also evidence for compensatory behavioral changes (increased puff volume and frequency and increased numbers of cigarettes smoked) (Djordjevic et al., 2000; Kabat, 2003) that result in altered smoke composition (Counts et al., 2005) and increased exposure to harmful components of cigarette smoke. Of potentially greater concern is evidence that cigarette smoke condensates (CSC) from low-nicotine cigarettes are more toxic to normal human bronchial epithelial (NHBE) cells than CSC from high-nicotine cigarettes, possibly due to nicotine-mediated suppression of apoptotic pathways (Chen et al., 2008). Therefore, understanding the consequences of differences in smoke composition as a function of cigarette design and smoking behavior is important in reducing the health burden of cigarette smoking.

Previous studies have successfully demonstrated differences in toxicity among different cigarette types or cigarette smoke fractions. Several studies (Fukano et al., 2006a,b; Hoshino et al., 2001; Lannan et al., 1994) have investigated the effects of smoking machine-generated CSC or whole smoke on cultured cell lines, particularly A549 cells, a transformed cell line with some characteristics of alveolar type II cells. Comparison of the effects of whole smoke and filtered smoke from "light" cigarettes sold in different countries with that of 
a research cigarette blended to be representative of a U.S. light cigarette in A549 cells showed differences in a dose-dependent depletion of reduced glutathione among the cigarette types (Ritter et al., 2004).

There have also been efforts to understand the metabolic targets of cigarette smoke exposure. Differences were observed between the effects of whole smoke and the gas/vapor phase from a single cigarette type on the metabolic pathways of human lung epithelial cells (Vulimiri et al., 2009), suggesting that cigarette smoke fractions can affect these pathways differentially. Exposure of NCI-H292 cells, a human lung epithelial cell line, to whole smoke demonstrated increases in expression of Muc5AC, an important form of mucin, and release of interleukin (IL)-6, IL-8, and MMP1 (Phillips et al., 2005). Another study suggested changes in genes regulating DNA damage, cell cycle, inflammation, and oxidative defense in cigarette smoke-exposed NHBE cells (Fields et al., 2005).

Gene expression arrays have considerable potential for identification of potential biomarkers of exposure and effect (Sen et al., 2007). To better define the effect of a wide range of CSCs on human respiratory tract cells, the present study was designed to analyze CSC-induced patterns of gene expression in NHBE cells. A previous study using a similar set of CSCs showed some differences in their mutagenicity as a function of total tar content but a much larger range based on nicotine content (DeMarini et al., 2008). Therefore, in the current study, the CSCs were compared at doses of nicotine concentrations that were minimally toxic.

\section{MATERIALS AND METHODS}

Cigarette smoke condensates. The cigarette types used in the study and the range in nicotine content are illustrated in Table 1. Cigarette smoke was generated at the CSC under the standard Federal Trade Commission (FTC) or Massachusetts intense (MI) method using a single port smoking machine $(\mathrm{CH}$ Technologies, Westwood, NJ) to a butt length of $23 \mathrm{~mm}$ or filter overwrap +3 mm, whichever was greater. Samples 1-9 (CSC1-CSC9) were smoked according to FTC conditions (35-ml puff volume, 2-s puff, and 1 min between puffs), and CSC10 was smoked according to the MI conditions (45 $\mathrm{ml}$ puff volume, 2-s puff, 30-s interval, and ventilation holes $50 \%$ blocked). CSC were prepared by bubbling the mainstream smoke through $10 \mathrm{ml}$ of PBS in a 30-ml midget bubbler (Kontes, Vineland, NJ); this solution, defined as " $100 \%$ CSC," was filtered through a $0.22-\mu \mathrm{m}$ filter, aliquoted, and kept frozen. To ensure consistency of exposures, separate aliquots of the frozen stock were used for each experiment.

Cells. Primary human bronchial/tracheal epithelial cells were purchased from Clonetics (now Lonza, East Rutherford, NJ). A single male, nonsmoking Caucasian donor was used for all experiments. The cells were cultured in 100-mm dishes in Bronchial Epithelial Cell Growth Medium (with retinoic acid) as recommended by the supplier. Approximately 8-10 doublings after purchase, cells were plated at a density of $2.8 \times 10^{5}$ cells per $100-\mathrm{mm}$ dish for the experiments. When cells were $70 \%$ confluent, at 6 days after plating, they were treated with CSC or with PBS for the control cultures. NHBE cells were treated with CSC from the various cigarettes at doses that represent a final nicotine concentration of $\sim 4 \mu \mathrm{g} / \mathrm{ml}$ for $18 \mathrm{~h}$ or for the viability measurements, a range of concentrations of the CSCs on a volume basis. All dosing was performed in duplicate, including the nontreated controls.
TABLE 1

Smoke Types and Nicotine Content Provided by the CDC

\begin{tabular}{|c|c|c|c|c|}
\hline $\begin{array}{l}\text { Smoke } \\
\text { type code }\end{array}$ & Cigarette & Abbreviation & $\begin{array}{l}\text { Smoking } \\
\text { machine } \\
\text { conditions }\end{array}$ & $\begin{array}{c}\text { Nicotine } \\
\text { (mg/cigarettes) }\end{array}$ \\
\hline $\mathrm{CSC} 1$ & $\begin{array}{l}\text { 2R4F Kentucky } \\
\text { reference cigarette }\end{array}$ & $2 \mathrm{R} 4 \mathrm{~F}$ & FTC & 0.75 \\
\hline $\mathrm{CSC} 2$ & $\begin{array}{l}\text { Commercial "low } \\
\text { nitrosamine", } \\
\text { cigarette }\end{array}$ & LNIT & FTC & 0.8 \\
\hline CSC 3 & $\begin{array}{l}\text { Experimental } 100 \% \\
\text { reconstituted } \\
\text { tobacco cigarette }\end{array}$ & REC & FTC & 0.8 \\
\hline $\mathrm{CSC} 4$ & $\begin{array}{l}\text { Commercial "low } \\
\text { ignition propensity" } \\
\text { cigarette }\end{array}$ & LIP & FTC & 0.6 \\
\hline CSC 5 & $\begin{array}{l}\text { Experimental } 100 \% \\
\text { burley tobacco } \\
\text { cigarette }\end{array}$ & BUR & FTC & 7.5 \\
\hline CSC 6 & $\begin{array}{l}\text { Experimental } 100 \% \\
\text { flue-cured tobacco } \\
\text { cigarette }\end{array}$ & BRI & FTC & 5 \\
\hline CSC 7 & $\begin{array}{l}\text { Commercial ultra } \\
\text { low-tar nonmenthol } \\
\text { cigarette }\end{array}$ & UL & FTC & 0.5 \\
\hline $\mathrm{CSC} 8$ & $\begin{array}{l}\text { Commercial full } \\
\text { flavor nonmenthol } \\
\text { cigarette }\end{array}$ & $\mathrm{FF}$ & FTC & 0.9 \\
\hline CSC 9 & $\begin{array}{l}\text { Commercial light } \\
\text { nonmenthol } \\
\text { cigarette }\end{array}$ & LT & FTC & 0.8 \\
\hline CSC 10 & $\begin{array}{l}\text { Commercial light } \\
\text { nonmenthol } \\
\text { cigarette }\end{array}$ & LTMAS & MI & 1.6 \\
\hline
\end{tabular}

Viability using water-soluble tetrazolium assay. Cells were cultured in 96-well tissue culture plates and treated in triplicate with a range of concentrations of the CSCs from 0.1 to $25 \%$ in culture medium. Following $18 \mathrm{~h}$ of incubation, the culture medium was removed and replaced with a $1: 10$ dilution of water-soluble tetrazolium (WST; Roche). The color change resulting from the conversion to the formazan was measured in the medium using a Versamax plate reader (Molecular Devices, Inc.).

Preparation of RNA. Total RNA was extracted and purified with Qiagen RNeasy kit from each sample (Qiagen, Valencia, CA). The total RNA concentrations were measured using the NanoDrop ND-1000 (ThermoScientific, Wilmington, DE), and RNA integrity was checked using Agilent 2100 Bioanalyzer to assure sufficient quality before proceeding with microarray hybridization.

Microarray hybridization. Affymetrix Human U133 2.0 Plus GeneChips were used for gene expression analysis. All procedures were performed according to the manufacture's instructions (Affymetrix, Santa Clara, CA). Briefly, $1.0 \mu \mathrm{g}$ of total RNA was used to generate double-stranded complementary DNA (cDNA) using an oligo dT-primer containing the T7 RNA polymerase promoter site and the One-Cycle Target Labeling Kit (Affymetrix). cDNA was purified via column purification using the GeneChip Sample Cleanup Module (Affymetrix), and biotinylated complementary RNA (cRNA) was synthesized by in vitro transcription using the GeneChip IVT Labeling Kit (Affymetrix). Biotin-labeled cRNA was purified and the absorbance measured at $260 \mathrm{~nm}$ to determine yield (NanoDrop). Twenty micrograms of the labeled cRNA was fragmented and hybridized to the 
Affymetrix GeneChip HG U133 2.0 Plus arrays for $16 \mathrm{~h}$ at $45^{\circ} \mathrm{C}$ following the Affymetrix protocol specific to this array type. Washing and staining were performed on the Affymetrix Fluidics 450 station according to the antibody amplification protocol (EukGE-Ws2v5; Fluidics script). The GeneChips were scanned using the Affymetrix GeneChip Scanner 3000.

After scanning, the microarrays were normalized using the Affymetrix Microarray Suite 5.0 (MAS 5.0). Signal values were scaled by global methods to a target value of 500. A pivot table was generated from MAS 5.0 and imported into GeneSpring GX (version 7.3; Agilent Technologies). The mean signal value for the two replicates for each of the samples was compared to the mean signal value of the two undosed control samples. For each of the pairwise comparisons, the 54,681 transcripts were first filtered to retain transcripts that had signal values above the background ( $>150 \mathrm{RFU}$ in one of two samples, either treated or control). The background/noise level is $\sim 75 \mathrm{RFU}$ for these arrays. Next, filtering was performed to keep transcripts that change at least twofold (up or down) compared to the control. The resulting gene lists, for each of the 10 samples, were then used to identify genes that were common to the 10 samples and to select genes that were unique to the 10 samples. The Affymetrix microarray data for this experiment have been submitted to the gene expression omnibus (GEO) repository and can be accessed under GEO record GSE18235.

Quantitative expression analysis by quantitative real-time PCR. RNA from each treatment that was not used for microarray hybridization was kept frozen at $-80^{\circ} \mathrm{C}$ in a dried state. After microarray analysis was completed, RNA was reconstituted in water and the concentration determined using the NanoDrop ND-1000 spectrophotometer. The 260:280 and 260:230 nm ratios were calculated by the NanoDrop spectrophotometer and used to evaluate the RNA purity. All samples had sufficient RNA for quantitative real-time PCR (qRT-PCR) except for the sample from NHBE cells treated with REC.

The primers and probes for growth differentiation factor 2 (BMP-9) (Hs00211913_m1), NAD(P)H dehydrogenase, quinone 1 (NQO-1) (Hs00168547_m1), cytochrome P450, family 1, subfamily A, polypeptide 1 (CYP1A1) (Hs00153120_m1), matrix metallopeptidase 1 (interstitial collagenase) (MMP-1) (Hs00233958_m1), and the housekeeping gene CDKN1B (hs00153277_m1) were from Applied Biosystems Inc.

The TaqMan Universal PCR Master Mix was distributed into the 96-well plate and each RNA (200 ng) sample in triplicates was added to the reaction mix. The primer/probe sets were added to each well and target messenger RNAs (mRNAs) were amplified by real-time PCR in $20-\mu 1$ reactions in the ABI PRISM 7900 HT real-time PCR system. For all reactions, CT values > 37 were eliminated for evaluation of preamplification efficiency. A standard linear model was applied to the qRT-PCR data to determine whether expression levels in CSC-treated NHBE cells showed differences from the control group. Because all results were derived from the linear amplification curve, the use of $\Delta \Delta \mathrm{CT}$ method ensures that only mRNA amplification within the linear range was compared.

Analysis of protein expression. Lysates of the cultures were prepared, and protein concentration was determined using a Bradford protocol (Bio-Rad, Hercules, CA) with bovine serum albumin (BSA) as the standard. Samples were denatured in Laemmli sample buffer at $95^{\circ} \mathrm{C}$ for $5 \mathrm{~min}$, and aliquots consisting of $15 \mu \mathrm{g}$ of protein along with Cruz-compatible standards (Santa Cruz Biotechnology, Santa Cruz, CA) and prestained molecular weight standards were loaded on $10 \%$ SDS-polyacrylamide gels with a $3 \%$ stacking gel using a MiniProtean III electrophoresis system (Bio-Rad). Proteins were electroblotted onto polyvinylidene fluoride membranes. The blots were stained with Ponceau S and then blocked with 5\% nonfat dry milk $+3 \%$ BSA and $0.2 \%$ Tween-20 in Tris-buffered saline (TBS). Primary antibodies (rabbit antiNQ01, Santa Cruz 25591 or anti-CYP1A1, Santa Cruz 20772) diluted 1:200 and/or mouse anti- $\beta$-actin (Santa Cruz 47778) diluted 1:1000 were added in TBS containing $1 \%$ BSA and $0.2 \%$ Tween-20 (TBS-wash) and incubated $2 \mathrm{~h}$ at room temperature. The blots were washed with the diluent and secondary antibodies (horseradish peroxidase [HRP]-conjugated goat anti-rabbit, Santa Cruz 2030) and/or alkaline phosphatase-conjugated goat anti-mouse (Sigma) at 1:1000 in TBS-wash were added. Blots were washed and developed with Lumigo (KPL HRP substrate) or CDP-Star (APase substrate; Sigma), and images were acquired using a Fuji imaging system (Woodbridge, CT). Bands corresponding to the target proteins were identified by molecular weight and quantified using MultiGauge software. Data are reported as the ratio of the target protein intensity to $\beta$-actin.

Measurement of released cytokines by Luminex. The following proteins were assayed in the conditioned medium from cells treated for $18 \mathrm{~h}$ with CSC: granulocyte-macrophage colony stimulating factor (GM-CSF), interferon $\gamma$, IL$1 \beta$, IL-2, IL-4, IL-5, IL-6, IL-8, IL-10, and tumor necrosis factor $\alpha$ were measured using a bead-based multiplex system (Biosource 10-plex human cytokine), using a Bioplex 100 instrument (Bio-Rad) according to the supplier's recommendations. CSC preparations were tested at constant dilutions of the CSC $(0.1$ and $5 \%)$ as well as at constant low-nicotine $(0.08 \mu \mathrm{g} / \mathrm{ml})$ and highnicotine $(4 \mu \mathrm{g} / \mathrm{ml})$ concentrations.

Statistical analysis. Results are presented as percent of control or fold change. Correlations between the various measures of altered gene expression or protein content were determined by plotting pairs of parameters for each sample ( $4 \mu \mathrm{g} / \mathrm{ml}$ doses only). Linear regression was performed using GraphPad Prism version 5.0, and coefficients of determination $\left(r^{2}\right)$ and $p$ values, calculated from an $F$-test, are reported.

\section{RESULTS}

\section{Cell Viability}

None of the CSCs were overtly toxic at concentrations of $<5 \%$. In fact, there was a substantial increase in the WST conversion rate for all CSC types at the 2.5 and $5 \%$ levels (Fig. 1). However, all CSC types were toxic at concentrations of $25 \%$. 2R4F, LIP, and LTMAS produced less than $50 \%$ of

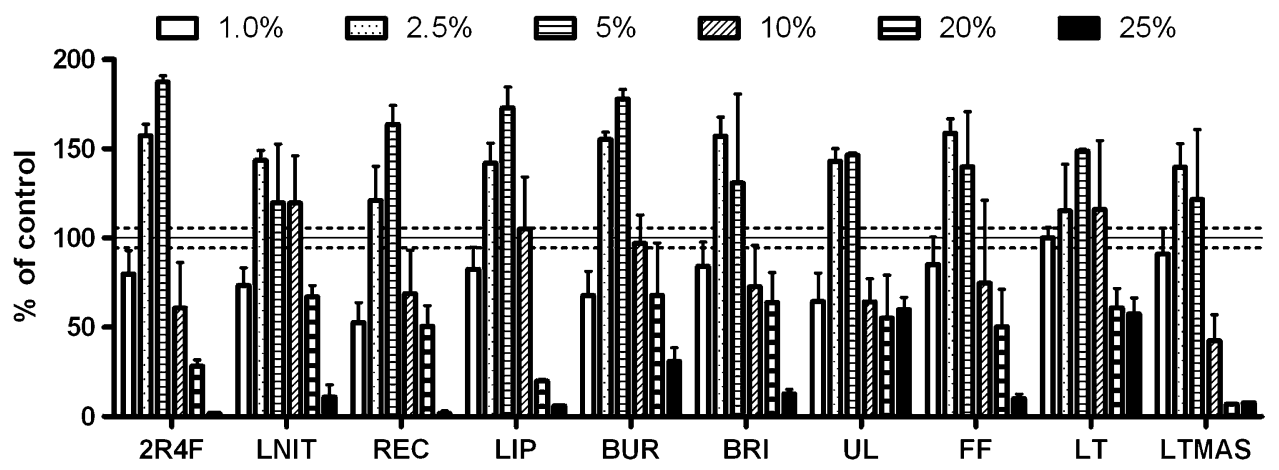

FIG. 1. CSC toxicity. CSC was diluted in culture medium to the indicated concentrations, and cells were exposed for $18 \mathrm{~h}$ prior to analysis of mitochondrial function using WST. Data indicate the percent of the control values (no CSC) and the SE. Horizontal lines show the range of the controls (mean and SEM). 
the control signal at $20 \%$. Only LTMAS produced $<50 \%$ of the control signal at the $10 \%$ concentration. For subsequent experiments, the exposures were normalized to similar nicotine content, $\sim 4 \mu \mathrm{g} / \mathrm{ml}(3.75-4.5 \mu \mathrm{g} / \mathrm{ml})$ nicotine that corresponds to $5 \%$ 2R4F, 5\% LNIT, 5\% REC, 6.6\% LIP, 0.5\% BUR, $0.8 \%$ BRI, $8 \% \mathrm{UL}, 5 \% \mathrm{FF}, 5 \% \mathrm{LT}$, and $2.5 \%$ LTMAS.

\section{Identification of Similarly Affected Genes}

After combining the genes from all 10 treatments with high signal values that were altered by at least twofold compared to controls, the genes were further sorted to identify those with differential expression found in at least 9 of the 10 treatment samples. Twenty-one genes that were found to meet these criteria are displayed as a heat map (Fig. 2A) and are listed in Table 2 along with their fold change relative to the control samples.

To validate the findings observed by microarray analysis, we selected 3 genes, CYPIAI, NQO-1, and BMP-9, from the list of 21 commonly changed in expression by 9 of the 10 cigarettes and that have been shown to have biological significance in responses to toxic exposures and to cigarette smoke. CYPIAl is a gene that encodes for an enzyme that metabolizes toxic compounds (DeMarini et al., 2008; Wardlaw et al., 1998). NQO-1 is an antioxidant gene (Ahn et al., 2006). Both of these genes were upregulated. In contrast, the gene that encodes for the secretory protein BMP-9, recently shown to act as a tumor suppressor (Ye et al., 2008) and anti-angiogenic factor (David et al., 2008), was strongly downregulated by CSC exposure. Because MMP-1 has a potential involvement in cigarette smoke-induced emphysema (Selman et al., 2003) and was previously shown to be elevated in a lung epithelial cell line following exposure to whole cigarette smoke (Phillips et al., 2005), it was also chosen for further analysis of its expression using qRT-PCR, although it was not among the top 21 genes as described above.

$B M P-9$ was not detected in any of the mRNA samples by qRT-PCR. Of the other three genes, CYPlAl was most strongly induced, followed by $N Q O-1$ (Fig. 2B). MMP- 1 was induced least. However, $2 \mathrm{R} 4 \mathrm{~F}$ induced CYP1Al $\sim 35$-fold, while the other CSCs induced the expression by 10- to 20 -fold except for BUR, FF, and LT, which induced expression $<10-$ fold. NQO-I and MMP-1 mRNA levels were increased between 5- to 10-fold by all cigarettes, except by BRI, BUR, and LT, which induced expression less than 5-fold. These results suggest some differences in the effect the CSCs have on expression of CYPIAI, NQOI, and MMP-1.

To further investigate the microarray and qRT-PCR results, we analyzed expression of CYP1A1 and NQO-1 proteins by Western blotting (Figs. 3A and 3B). Two of the proteins (MMP-1 and BMP-9) selected for analysis were not detected in any of the protein lysates by Western blot analysis. While NQO1 was detected at moderately low levels, CYP1A1 was detected at very low levels. Interestingly, expression levels of NQO-1 protein when normalized for $\beta$-actin was increased by some of the CSCs except for BUR, BRI, UL, and FF (Fig. 3C). While there were some trends for increases in CYP1A1 protein levels for several of the CSCs, the high variability precluded any of these reaching statistical significance (Fig. 3D). Linear regression was used to assess the $r^{2}$ and $p$ values for each comparison to determine whether the relative change in expression of NQO-1 and CYP1A1 correlated when measured by Affymetrix and Western analyses (Fig. 3E) A statistically significant correlation was observed for NQO-1 mRNA levels as quantified by microarray and the protein concentration quantified by Western blots (Fig. 3E) $\left(r^{2}=0.50, p=0.01\right)$. A similar correlation was observed between the qRT-PCR data and the Western analyses (data not shown). However, no correlation was found for CYPIAl mRNA levels quantified by microarray and protein concentrations by Western analysis $\left(r^{2}=0.03, p=0.63\right)$.

\section{Identification of Uniquely Affected Genes}

The genes uniquely modified in expression by each of the $10 \mathrm{CSCs}$ were selected using a series of Venn diagrams to exclude common genes found similarly modified in expression by the other 9 CSCs. This approach produced a list of genes that were differentially expressed by each CSC. For each CSC, the three most highly induced and three most repressed genes were selected and presented as a heat map (Fig. 4). In addition, the list of these genes along with their respective fold change compared to control samples is shown in Table 3.

\section{Effect of Various CSCs on Cytokine Secretion}

For additional characterization of the relative proinflammatory effects of the various CSCs, the secretion of 10 chemokines and cytokines were determined $18 \mathrm{~h}$ after treatment. GM-CSF, IL-1 $\beta$, and IL-6 were released at low levels in only one experiment and were therefore not considered reliable (data not shown), while IL-8 was released consistently in three independent experiments. All other cytokines tested were not detected in any of the conditioned medium. Treatment with REC, BRI, and LTMAS produced significant increases in IL-8 secretion (Fig. 5A). Of note, while the mRNA levels for IL-8 showed an increase by several CSCs (data not shown), this chemokine was not on the list of either commonly or uniquely induced genes. Of particular interest is the greater stimulation of IL-8 release by LTMAS compared to LT because these condensates were generated from the same cigarette under different machine-smoking conditions.

To observe whether there was a dose-dependent effect on IL-8 secretion, we generated dose-response curves for selected smoke types. CSCs that were generated from the same cigarette by different methods, LT (ISO method) and LTMAS (MI method), showed that the intense smoking machine method produced a greater proinflammatory response compared to smoke generated using the ISO method when diluted to the same nicotine concentration (Fig. 5B). For cigarettes that were 
A
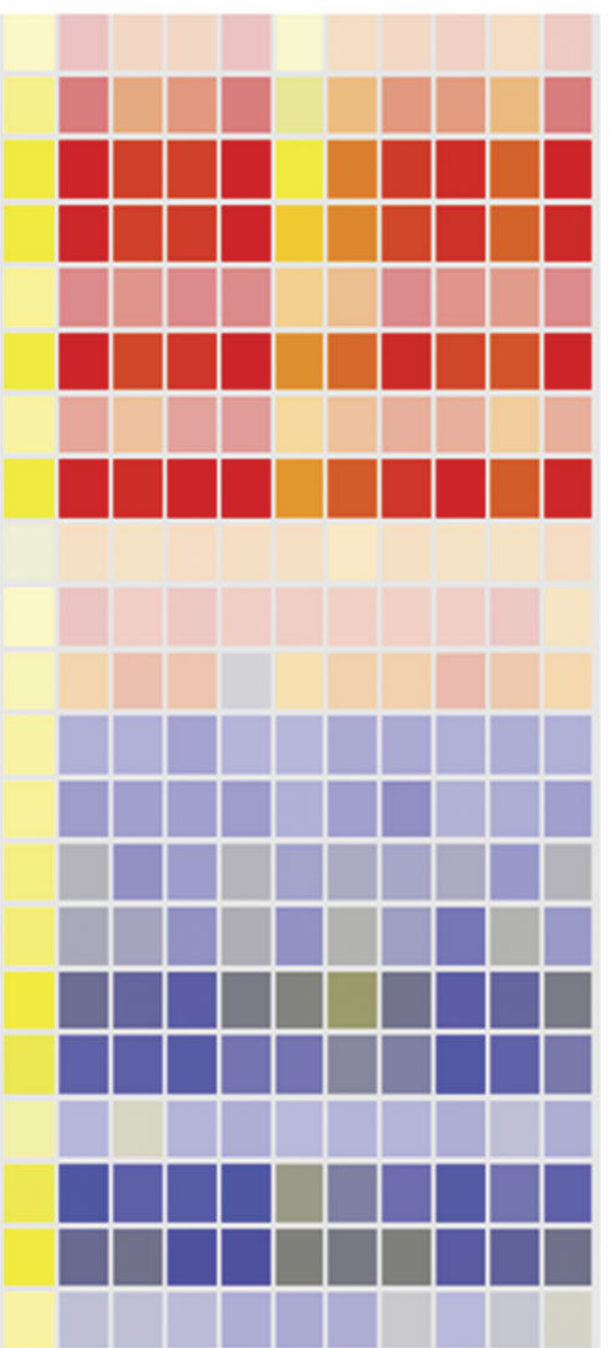

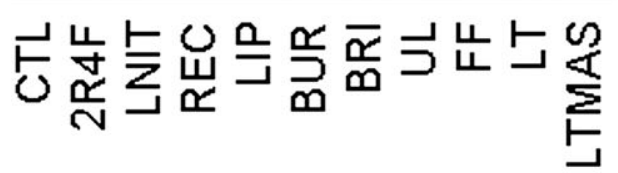

B.

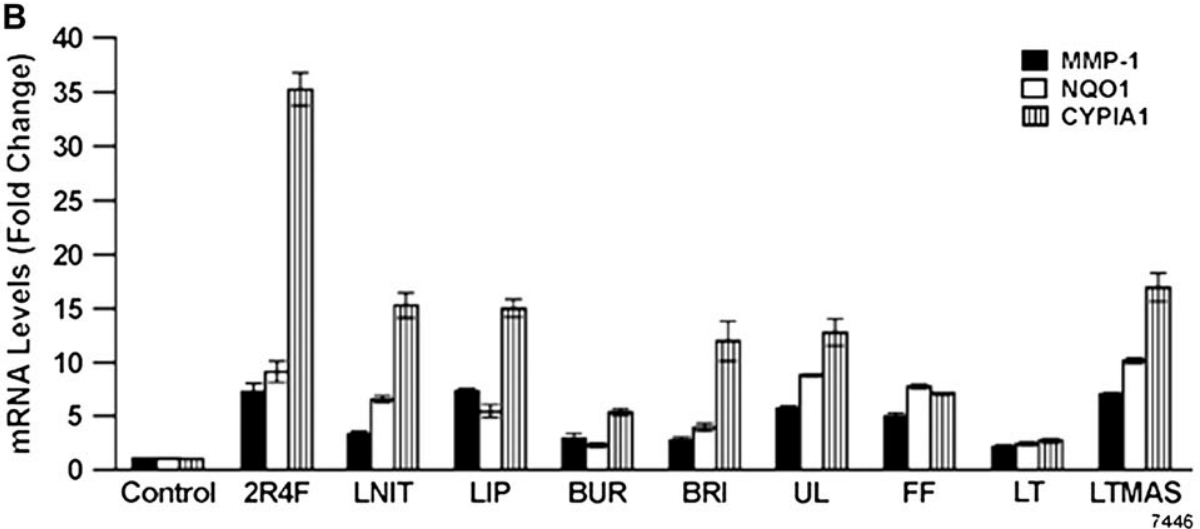

Gene Symbol

SAMD5

AKR1C1/C2

GPX2

NQO1

CYP1A1

CYP1B1

MAG1(AGPAT9)

TFRC

RAVER1

HTF9C

PGAR (ANGPTL4)

BE673671

Unknown

FBX032

LYPD6B

MXRA5

WNT4

BMP9 (GDF2)

BRAK (CXCL14)

METTL7A

PIG11(TP53|11)

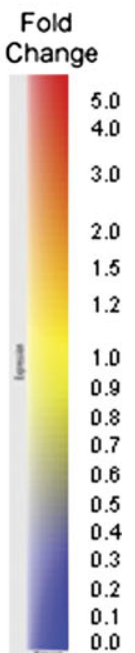


TABLE 2

Genes Changing in At Least 9 of 10 CSC Samples

Fold changes

\begin{tabular}{|c|c|c|c|c|c|c|c|c|c|c|c|c|}
\hline Gene symbol & Gene title & 2R4F & LNIT & REC & LIP & BUR & BRI & UL & $\mathrm{FF}$ & $\mathrm{LT}$ & LTMAS & Average \\
\hline SAMD5 & Sterile alpha motif domain containing 5 & 5.99 & 3.27 & 3.37 & 7.67 & -1.11 & 2.49 & 3.14 & 4.09 & 2.48 & 5.07 & 3.65 \\
\hline AKR1C1/C2 & Aldo-keto reductase family 1 , member $\mathrm{C} 1$ & 5.94 & 3.02 & 4.05 & 8.23 & -1.20 & 2.24 & 3.98 & 3.83 & 2.29 & 5.94 & 3.83 \\
\hline GPX2 & Glutathione peroxidase 2 (gastrointestinal) & 6.88 & 4.12 & 4.09 & 6.89 & 1.00 & 2.22 & 4.19 & 5.13 & 2.90 & 6.30 & 4.37 \\
\hline NQO1 & $\mathrm{NAD}(\mathrm{P}) \mathrm{H}$ dehydrogenase, quinone 1 & 5.73 & 4.14 & 4.37 & 6.31 & 1.21 & 2.09 & 3.81 & 4.80 & 2.88 & 5.44 & 4.08 \\
\hline CYP1A1 & $\begin{array}{l}\text { Cytochrome P450, family } 1 \text {, subfamily A, } \\
\text { polypeptide } 1\end{array}$ & 9.65 & 5.05 & 6.56 & 18.14 & 1.76 & 2.58 & 8.17 & 5.21 & 4.41 & 13.02 & 7.45 \\
\hline CYP1B1 & $\begin{array}{l}\text { Cytochrome } \mathrm{P} 450 \text {, family } 1 \text {, subfamily } \mathrm{B} \text {, } \\
\text { polypeptide } 1\end{array}$ & 6.27 & 3.69 & 4.44 & 8.56 & 1.89 & 2.67 & 5.37 & 3.80 & 3.42 & 6.48 & 4.66 \\
\hline MAG1(AGPAT9) & $\begin{array}{l}\text { 1-Acylglycerol-3-phosphate } O \text { - } \\
\text { acyltransferase } 9\end{array}$ & 4.50 & 2.72 & 5.17 & 5.66 & 1.72 & 2.67 & 4.07 & 4.07 & 2.20 & 4.12 & 3.69 \\
\hline TFRC & Transferrin receptor (p90, CD71) & 5.73 & 5.03 & 5.99 & 6.90 & 1.85 & 3.16 & 4.47 & 6.25 & 3.04 & 5.65 & 4.81 \\
\hline RAVER1 & Ribonucleoprotein, PTB-binding 1 & 2.18 & 2.12 & 2.5 & 2.42 & 2.22 & 1.6 & 2.16 & 2.01 & 2.03 & 2.56 & 2.19 \\
\hline HTF9C & HpaII tiny fragments locus 9C & 5.70 & 4.15 & 5.34 & 4.16 & 4.43 & 3.91 & 3.97 & 4.29 & 5.54 & 1.85 & 4.33 \\
\hline PGAR (ANGPTL4) & Angiopoietin-like 4 & 2.24 & 3.69 & 3.39 & -2.14 & 1.64 & 2.59 & 2.62 & 4.37 & 3.21 & 2.11 & 2.37 \\
\hline BE673671 & - & -4.63 & -4.41 & -9.80 & -4.07 & -3.61 & -6.10 & -6.49 & -4.74 & -4.90 & -4.61 & -5.34 \\
\hline Unknown & hCG2007354 & -6.58 & -5.49 & -5.38 & -6.76 & -3.13 & -5.24 & -13.02 & -2.85 & -3.33 & -5.08 & -5.69 \\
\hline FBX032 & - & -2.13 & -4.31 & -3.30 & -2.04 & -2.79 & -2.51 & -2.66 & -2.38 & -3.58 & -2.11 & -2.78 \\
\hline LYPD6B & LY6/PLAUR domain containing 6B & -2.17 & -2.34 & -3.64 & -2.09 & -3.48 & -2.02 & -2.60 & -8.93 & -1.95 & -2.79 & -3.20 \\
\hline MXRA5 & Matrix-remodeling associated 5 & -2.51 & -2.52 & -2.78 & -2.10 & -2.00 & -1.64 & -2.26 & -2.94 & -2.72 & -2.15 & -2.36 \\
\hline WNT4 & $\begin{array}{l}\text { Wingless-type MMTV integration site } \\
\text { family, member } 4\end{array}$ & -3.85 & -4.41 & -5.32 & -2.98 & -2.86 & -2.31 & -2.51 & -8.77 & -3.73 & -2.69 & -3.94 \\
\hline BMP9 (GDF2) & Growth differentiation factor 2 & -3.61 & -1.65 & -3.95 & -5.41 & -3.08 & -4.03 & -4.17 & -4.95 & -2.53 & -5.52 & -3.89 \\
\hline BRAK (CXCL14) & Chemokine (C-X-C motif) ligand14 & -10.22 & -4.24 & -5.56 & -12.67 & -1.83 & -2.48 & -3.04 & -5.92 & -2.82 & -3.76 & -5.25 \\
\hline METTL7A & Methyltransferase like 7A & -2.44 & -2.31 & -3.45 & -3.69 & -1.98 & -2.11 & -2.02 & -2.96 & -2.62 & -2.29 & -2.59 \\
\hline PIG11(TP53I11) & Tumor protein $\mathrm{p} 53$ inducible protein 11 & -2.65 & -2.72 & -2.82 & -5.08 & -5.99 & -5.05 & -2.08 & -3.31 & -2.27 & -1.75 & -3.37 \\
\hline
\end{tabular}

representative for the lowest (UL) and highest (BUR) nicotine levels, the dose-response curve showed very little effect at any dose of the high-nicotine cigarette, while a significantly increased IL-8 release was observed at the highest concentration of the low-nicotine commercial "ultralight" cigarette (Fig. 5C).

\section{DISCUSSION}

The present study investigated whether a wide range of commercial and experimental cigarettes affect NHBE cells by causing changes in gene expression and cytokine secretions in common or unique ways. All the CSCs similarly demonstrated a strong increase in expression of genes that coded for xenobiotic and detoxifying functions such as CYP1A1 and CYP1B1 and antioxidants such as GPX2 and NQO-1. The concordance among these responses increases confidence that these effects on gene expression are important biological events. These findings are consistent with previous reports showing gene changes in NHBE cells following exposure to cigarette smoke in vitro (Maunders et al., 2007) or in airway cells obtained by brushings from smokers (Spira et al., 2004) and in animal studies (Gebel et al., 2004). It has been proposed that respiratory epithelial cells respond to cigarette smoke by enhancing the activity of the antioxidant system to prevent damage by lung toxicants (Lannan et al., 1994). This response by airway cells can be important for disease development because an inadequate response to oxidative stress is implicated as a major risk factor for chronic obstructive pulmonary disease (Bowler et al., 2004; MacNee, 2000; Rangasamy et al., 2009)

While the protein levels for CYP1A1 did not correlate with the fold changes determined by the microarray or qRT-PCR, a good correlation was found for changes in NQO-1 mRNA and protein levels by the various cigarette types. It is possible that the low protein levels detected for CYP1A1 by Western blot analysis did not allow for reliable quantitation due to poor signal-to-noise ratio. Therefore, lack of reliable quantitation could have contributed to the lack of correlation with the mRNA measurements. However, it is also possible that protein levels are regulated by protein stability or other mechanisms that are independent of mRNA levels. Future studies need to clarify this discrepancy.

MMP-1, while detected by qRT-PCR, was not detected by immunoblotting, suggesting that this protein is expressed at very low levels. However, previous reports have also shown that MMP-1 is induced in NHBE cells exposed to cigarette 
A

NQO1

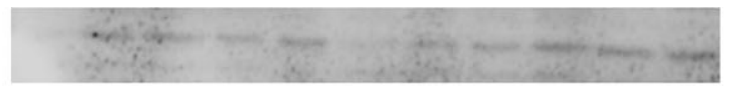

BActin

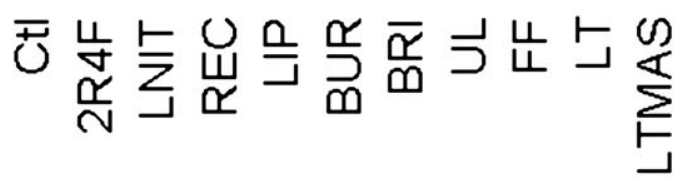

B

\title{
CYP1A1
}

\author{
BActin
}

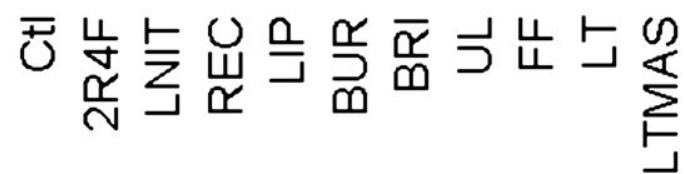
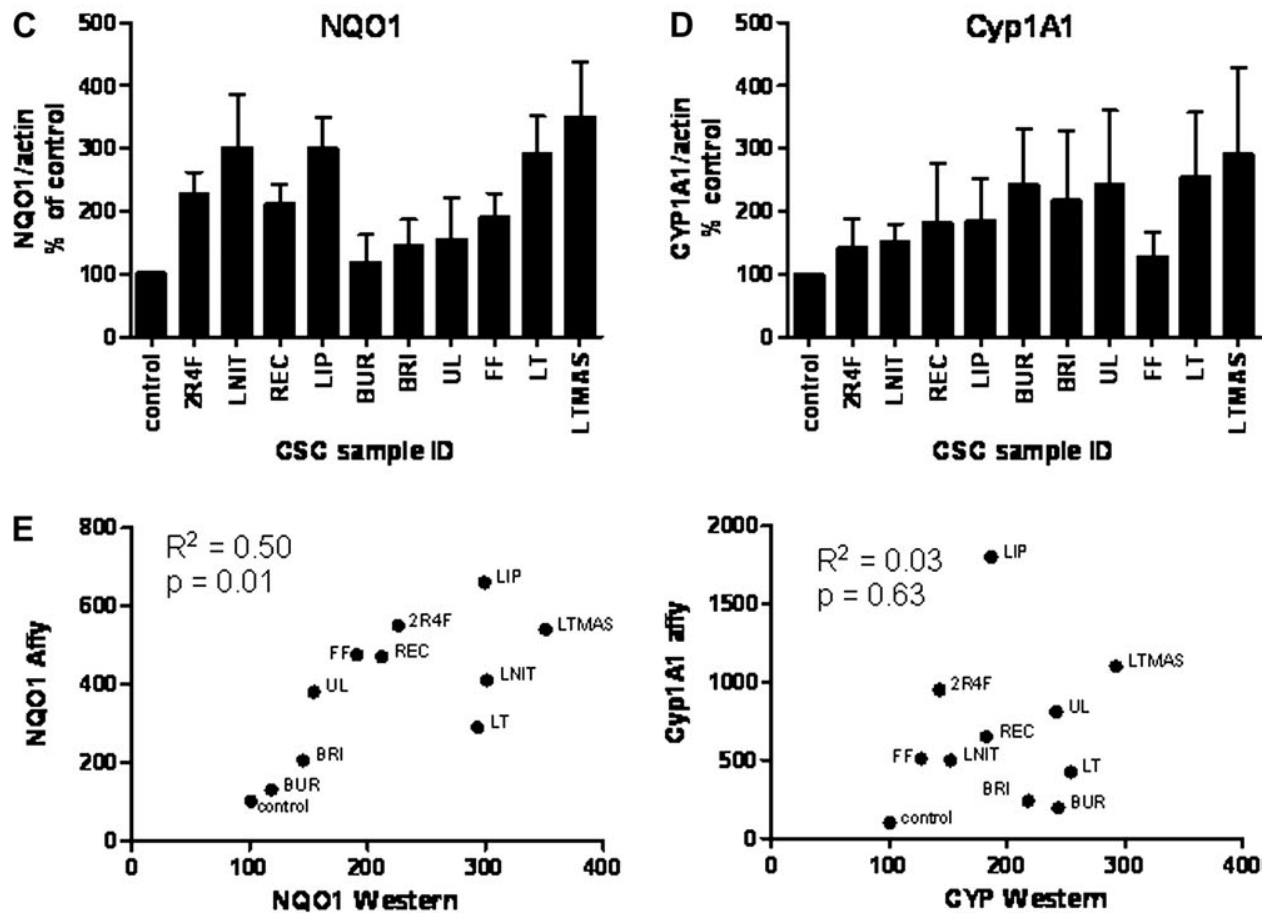

FIG. 3. Analysis of expression for NQO1 (A) and CYP1A1 (B) by Western blot analysis. Protein levels were normalized using $\beta$-actin levels (C and D) from three representative Western blots. (E) Relative concentrations of NQO1 (left) and CP1A1 (right) as measured by Affymetrix and Western blots (normalized to $\beta$-actin) were compared. Linear regression was used to assess the correlation coefficient $\left(R^{2}\right)$ and the $p$ values for each comparison.

smoke (Imai et al., 2001; Maunders et al., 2007; Mercer et al., 2004). It is possible that proteins such as MMP-1 are expressed at levels that are sufficient to cause destruction to the lung by acting in their immediate surroundings but will be difficult to detect by conventional methods, such as Western blotting.

BMP-9 showed a strong downregulation by microarray analysis but was not detected either by qRT-PCR or by
Western blotting. These findings suggest that $B M P-9$ expression levels are low in control cells; therefore, further downregulation cannot be verified by these detection techniques. The reason for the discrepancy between the two mRNA quantitation methods is not entirely clear, but it could simply be the result of a greater sensitivity of the array. Alternatives include the possibility that the oligo used by the array detected 


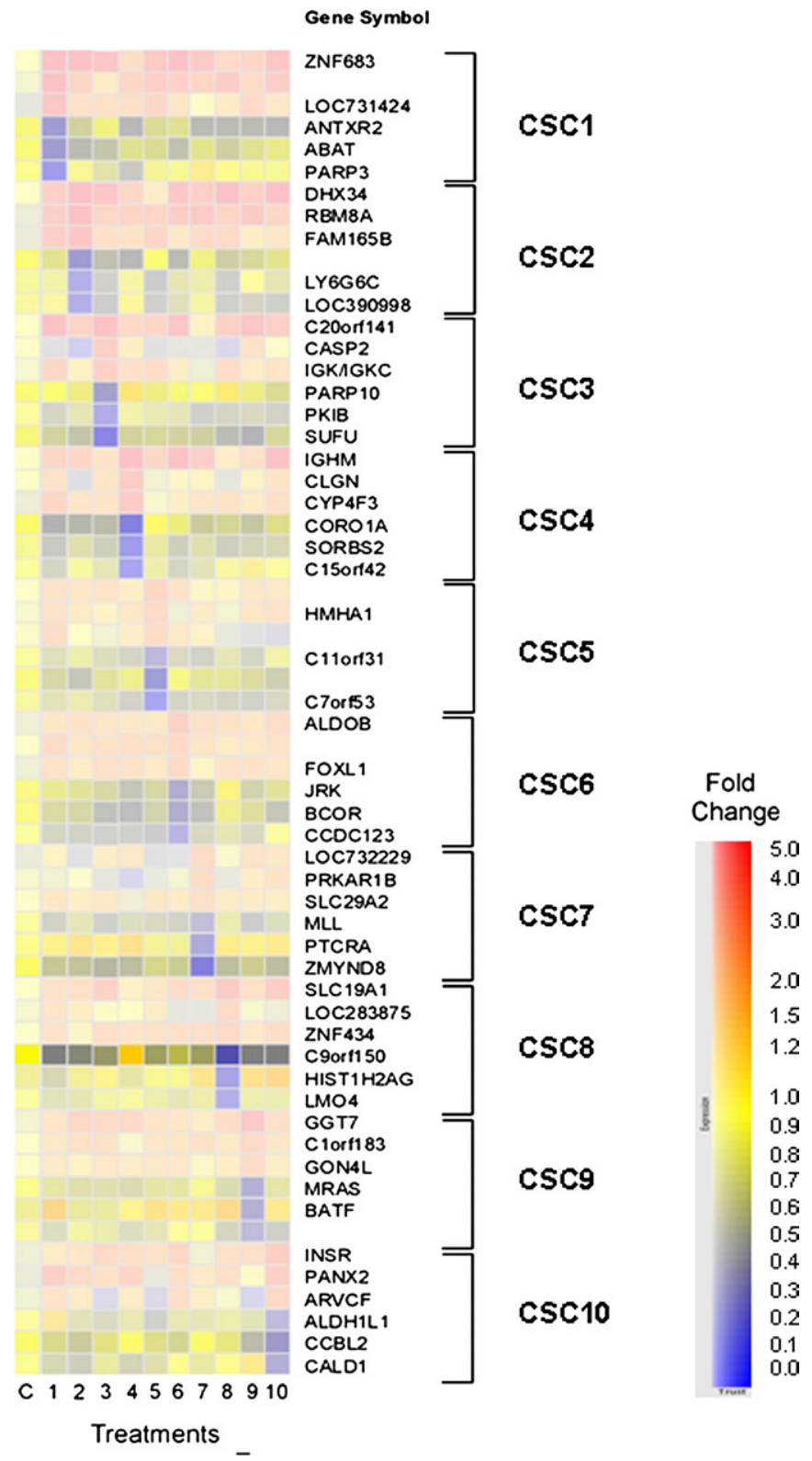

FIG. 4. Heat map of genes that were uniquely modified by the 10 cigarette types. For each cigarette, three upregulated and three downregulated genes were selected that were modified in expression at least twofold. Gene transcripts that are induced by CSC treatment are colored red and genes that are downregulated are colored blue. Thus, the color indicates the fold induction for each independent gene and the intensity indicates the absolute signal values for that specific gene.

a similar gene product, not similar in the same regions used for the primers/probe for the qRT-PCR. Pathway mapping analyses of the expression data using Systems Biology and Pathway Analysis (GeneGo Software, Encinitas, CA) suggested that the Wnt and BMP-9 signaling pathways were strongly downregulated by all cigarette types (data not shown). Downregulation of the Wnt receptor and the TGF- $\beta$ signaling pathways have been found for NHBEs exposed to cigarette smoke (Maunders et al., 2007).
TABLE 3

List of Genes Uniquely Affected by Cigarette Smoke Type

\begin{tabular}{|c|c|c|c|}
\hline $\begin{array}{l}\text { Cigarette } \\
\text { type }\end{array}$ & Probeset ID & Gene name & $\begin{array}{l}\text { Fold } \\
\text { change }\end{array}$ \\
\hline 2R4F & 230756_at & ZNF683 & 11.22 \\
\hline 2R4F & 237274_at & & 7.23 \\
\hline 2R4F & 1569095_at & LOC731424 & 5.50 \\
\hline 2R4F & 1555536_at & ANTXR2 & -3.05 \\
\hline 2R4F & 209460_at & $\mathrm{ABAT}$ & -3.27 \\
\hline 2R4F & 209940_at & PARP3 & -3.51 \\
\hline LNIT & 204815_s_at & DHX34 & 8.87 \\
\hline LNIT & 1554602_at & RBM8A & 5.88 \\
\hline LNIT & 1554430_at & FAM165B & 5.46 \\
\hline LNIT & 215907_at & & -2.83 \\
\hline LNIT & 207114_at & LY6G6C & -2.84 \\
\hline LNIT & 216589_at & LOC390998 & -3.02 \\
\hline REC & 1554042_s_at & C20orf141 & 7.57 \\
\hline REC & 209812_x_at & CASP2 & 4.12 \\
\hline REC & 224795_x_at & IGK/IGKC & 3.85 \\
\hline REC & 229350_x_at & PARP10 & -2.69 \\
\hline REC & 223551_at & PKIB & -2.94 \\
\hline REC & 222749_at & SUFU & -4.83 \\
\hline LIP & 209374_s_at & IGHM & 9.54 \\
\hline LIP & 205830_at & CLGN & 7.02 \\
\hline LIP & 206515_at & CYP4F3 & 5.45 \\
\hline LIP & 209083_at & CORO1A & -4.25 \\
\hline LIP & 225728_at & SORBS2 & -6.41 \\
\hline LIP & 232475_at & C15orf42 & -7.81 \\
\hline BUR & 1565617_at & & 3.27 \\
\hline BUR & 212873_at & HMHA1 & 3.04 \\
\hline BUR & 221715_at & & 2.78 \\
\hline BUR & 228331_at & C11orf31 & -3.26 \\
\hline BUR & 244411_at & & -3.99 \\
\hline BUR & 239203_at & C7orf53 & -4.30 \\
\hline BRI & 216600_x_at & ALDOB & 3.90 \\
\hline BRI & 239959_x_at & & 3.04 \\
\hline BRI & 243409_at & FOXL1 & 2.69 \\
\hline BRI & 214692_s_at & JRK & -2.52 \\
\hline BRI & 223915_at & BCOR & -2.53 \\
\hline BRI & 1563919_a_at & CCDC123 & -3.24 \\
\hline UL & 241904_at & LOC732229 & 2.76 \\
\hline UL & 212555_at & PRKAR1B & 2.68 \\
\hline UL & 1553540_a_at & SLC29A2 & 2.59 \\
\hline UL & 216624_s_at & MLL & -2.68 \\
\hline UL & 215492_x_at & PTCRA & -2.84 \\
\hline UL & 214795_at & ZMYND8 & -3.10 \\
\hline FF & 1555952_at & SLC19A1 & 9.91 \\
\hline FF & 230525_at & LOC283875 & 3.61 \\
\hline FF & 220292_at & ZNF434 & 2.93 \\
\hline FF & 227443_at & C9orf 150 & -3.18 \\
\hline FF & 208583_x_at & HIST1H2AG & -3.30 \\
\hline FF & 227155_at & LMO4 & -3.44 \\
\hline LT & 226470_at & GGT7 & 5.19 \\
\hline LT & 220476_s_at & C1orf183 & 3.02 \\
\hline LT & 219846_at & GON4L & 2.78 \\
\hline LT & 225185_at & MRAS & -2.54 \\
\hline LT & 205965_at & BATF & -2.55 \\
\hline LT & 239991_at & & -2.66 \\
\hline
\end{tabular}


TABLE 3-Continued

\begin{tabular}{lllr}
\hline $\begin{array}{l}\text { Cigarette } \\
\text { type }\end{array}$ & Probeset ID & Gene name & $\begin{array}{r}\text { Fold } \\
\text { change }\end{array}$ \\
\hline LTMAS & 226216_at & INSR & 4.38 \\
LTMAS & 239067_s_at & PANX2 & 4.13 \\
LTMAS & 205784_x_at & ARVCF & 2.91 \\
LTMAS & 205208_at & ALDH1L1 & -2.69 \\
LTMAS & 1556336_at & CCBL2 & -2.72 \\
LTMAS & 235834_at & CALD1 & -3.04 \\
\hline
\end{tabular}

While these oxidant and metabolism-related genes were induced by all cigarette types, certain genes were uniquely affected by the different cigarettes. These genes are difficult to group into certain pathways at this time, but pathway analysis may help to interpret their expression. Further research and analysis are needed to determine if these genes are appropriate as biomarkers for exposure to cigarettes that vary in tobacco blend, machine-generated smoke yield, or other design aspects. As previously mentioned, tobacco type can influence the mainstream smoke delivery of nicotine and other chemicals. For example, nitrate and nitrogen-derived chemicals such as the tobacco-specific nitrosamines and ammonia are higher in burley tobacco (e.g., BUR) (Ding et al., 2008; Rodgman and Perfetti, 2008), while flue-cured tobacco (e.g., BRI) has higher levels of polyaromatic hydrocarbon compounds, hydroquinones and catechol (Ding et al., 2008; Wooten et al., 2006). These observations may be relevant in the observation that responses to BUR differed from the other types within the group of upregulated genes.

We detected increases in the mRNA and protein levels of proinflammatory chemokine IL-8, which is not unexpected given the considerable literature indicating responses of this mediator to exposure to a range of environmental agents (Baeza-Squiban et al., 1999) and CSCs (Fields et al., 2005; Kabat, 2003). In addition, the data from the microarray analyses in general corroborated with the cytokine secretion results (data not shown). The effect does not correlate directly with nicotine dose because at similar nicotine levels, LIP and UL (both low nicotine), BRI (high nicotine), and LTMAS (same cigarette as LT) caused the largest increases in IL-8 secretion. However, after correction for multiple comparisons, the effects of LIP and UL were not statistically significant, although the smaller increase induced by REC was significant. Importantly, toxicity as determined by the WST assay did not correlate with the ability to induce IL- 8 secretion. Clearly different cigarettes, and even the same cigarette smoked under different conditions, vary in the ratio of tar and other potentially toxic components; and the ratio between these and the nicotine content may have contributed to such findings. It is particularly noteworthy that the effect of the LTMAS was considerably stronger than that of LT, at the same nicotine dose. If there is validity to the concept that smokers use different smoking patterns to achieve the equivalent nicotine
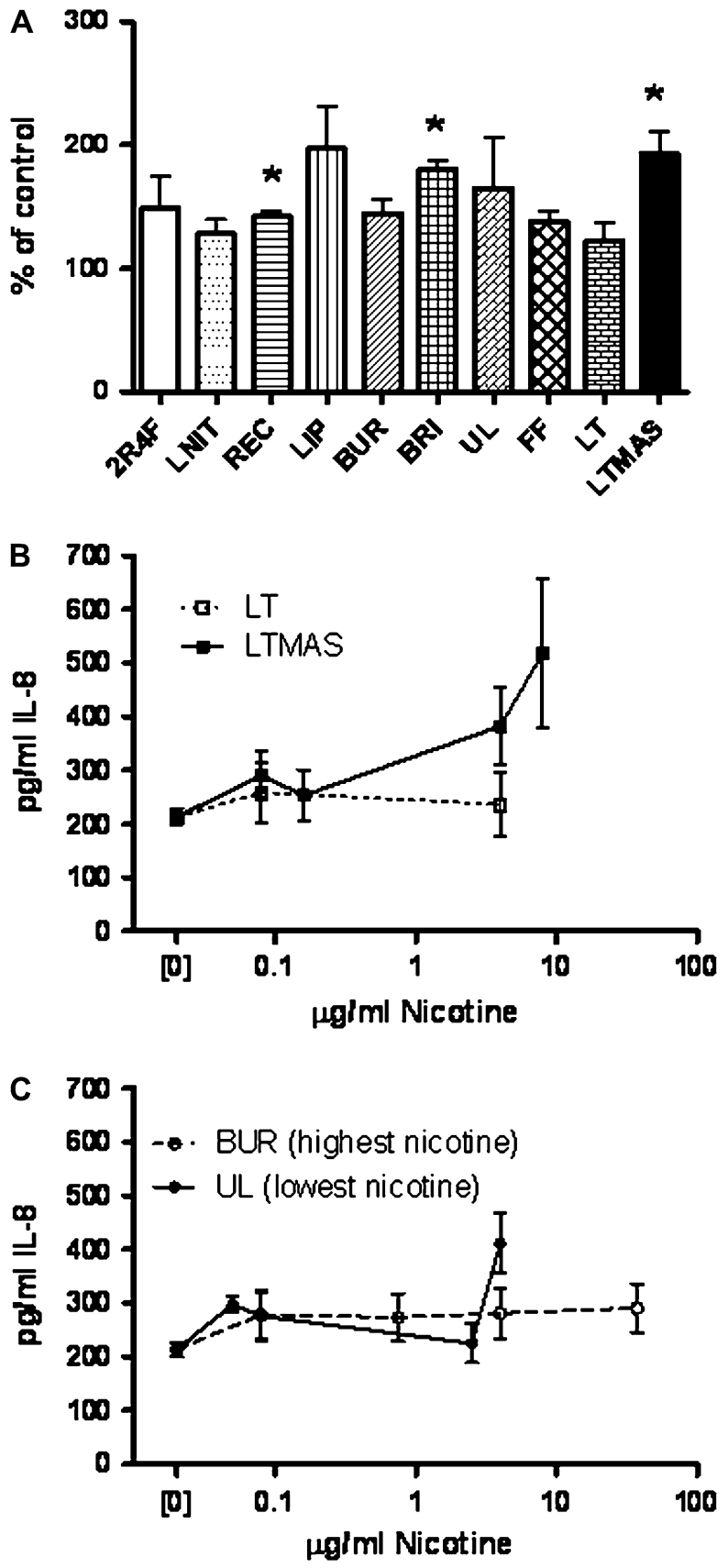

FIG. 5. (A) IL-8 secretion following $18 \mathrm{~h}$ of exposure to $4 \mu \mathrm{g} / \mathrm{ml}$ nicotine. Significant increases $\left({ }^{*} p<0.05\right)$ in IL-8 were found for REC, BRI, and LTMAS. The value for LIP, while elevated, did not reach statistical significance. This $4 \mu \mathrm{g} / \mathrm{ml}$ dose of nicotine was achieved with the following concentrations of the CSC: 2R4F, 5\%; LNIT, 5\%; REC, 5\%; LIP, $6.6 \%$; BUR, $0.5 \%$; BRI, $0.8 \%$; UL, $8 \%$; FF, $5 \%$; LT, $5 \%$; LTMAS, $2.5 \%$. Dose-response for IL-8 production from two samples from the same cigarette smoked under different conditions (B) and from cells treated with the CSCs with the highest and lowest nicotine content $(\mathrm{C})$.

dose, the reduced-nicotine content cigarettes may provide greater loads of these other toxins.

The strength of this study is that gene expression changes across 9 cigarette types and 10 CSCs were investigated and a 
subset of these genes was validated by qRT-PCR and Western blotting. The results show that 9 cigarette types and $10 \mathrm{CSCs}$, including one that has been referred to as a "reduced exposure cigarette," affected gene expression associated with xenobiotic metabolism and detoxifying functions. These findings suggest that humans with deficiencies in these protective mechanisms will experience a higher level of negative health effects. Because the exposures were performed at the same nicotine content, the results indicate that the probability of adverse health effects is increased regardless of the type of cigarette smoked. While this message has been suggested by others (e.g., Chen et al., 2008), our study shows evidence for the detrimental effect of cigarettes based on expression profiling studies over a much larger number of cigarette smoke types. In addition, we identified unique gene expression response patterns. These biomarkers could potentially be used in future research to study CSCs that differ in machine-generated smoke yield or other design characteristics and in identifying the specific components that induce particular responses.

One limitation of the present study is that NHBEs were exposed to smoke condensates and not whole smoke from the various cigarettes. The use of CSC for treatment implies that certain smoke components, in particular the vapor phase, are excluded due to differences in volatility, solubility, or stability. The effect of these components could have significant effects on gene expression, which may be responsible for significant toxicological effects. A second limitation is the use of a single time point. Previous studies (reviewed Sen et al., 2007) have suggested transient effects following exposures.

In our studies, various cigarette types were tested in NHBE cells from one individual. This approach removes the problem associated with interpretation of interindividual variability but also cannot provide information on how NHBE cells from various subjects may respond due to genetic variation. In addition, the cells were used under conditions where they are not fully differentiated by culture at air-liquid interface, which could affect their responses. Future studies should involve NHBEs from various individuals to appreciate the range of effect or similar responses and should ideally be performed with fully differentiated cells exposed to fresh whole smoke.

Because inflammation is part of the effect on the airway epithelial cells, future studies should also include exposure of rodents to fully evaluate differences in effects various cigarettes may have on the lung and health in general. Therefore, cigarettes should be tested in in vivo models of cigarette smoke-induced inflammation, chronic bronchitis, and emphysema, as has been done previously (Fields et al., 2005; March et al., 2006; Nikula et al., 2000; Seagrave et al., 2004).

\section{FUNDING}

U.S. Centers for Disease Control and Prevention and the Flight Attendant Medical Research Institute (\#CIA_062442 and 042281_CIA).

\section{ACKNOWLEDGMENTS}

We thank Marilee Morgan, Lois Herrera, Kurt Schwalm, David Palucki, Susan McGrath, and Brandy Crowder for technical assistance on selected experiments. The use of trade names is for informational purposes only and in no way implies endorsement or recommendation for use by the U.S. government, the U.S. Department of Health and Human Services, or the Centers for Disease Control and Prevention (CDC). The findings and conclusions in this article are those of the authors and do not necessarily represent the views of CDC.

\section{REFERENCES}

Ahn, K. S., Sethi, G., Jain, A. K., Jaiswal, A. K., and Aggarwal, B. B. (2006). Genetic deletion of NAD(P)H:quinone oxidoreductase 1 abrogates activation of nuclear factor-kappaB, IkappaBalpha kinase, c-Jun N-terminal kinase, Akt, p38, and p44/42 mitogen-activated protein kinases and potentiates apoptosis. J. Biol. Chem. 281, 19798-19808.

Baeza-Squiban, A., Bonvallot, V., Boland, S., and Marano, F. (1999). Airborne particles evoke an inflammatory response in human airway epithelium. Activation of transcription factors. Cell Biol. Toxicol. 15, 375-380.

Baker, R. R., da Silva, P., Jr, and Smith, G. (2004a). The effect of tobacco ingredients on smoke chemistry. Part I: flavourings and additives. Food Chem. Toxicol. 42(Suppl.), S3-S37.

Baker, R. R., da Silva, P., Jr, and Smith, G. (2004b). The effect of tobacco ingredients on smoke chemistry. Part II: casing ingredients. Food Chem. Toxicol. 42(Suppl.), S39-S52.

Bowler, R. P., Barnes, P. J., and Crapo, J. D. (2004). The role of oxidative stress in chronic obstructive pulmonary disease. COPD 1, 255-277.

Chen, J., Higby, R., Tian, D., Tan, D., Johnson, M. D., Xiao, Y., Kellar, K. J., Feng, S., and Shields, P. G. (2008). Toxicological analysis of low-nicotine and nicotine-free cigarettes. Toxicology 249, 194-203.

Counts, M. E., Morton, M. J., Laffoon, S. W., Cox, R. H., and Lipowicz, P. J. (2005). Smoke composition and predicting relationships for international commercial cigarettes smoked with three machine-smoking conditions. Regul. Toxicol. Pharmacol. 41, 185-227.

Das, S. K. (2003). Harmful health effects of cigarette smoking. Mol. Cell. Biochem. 253(1-2), 159-165.

David, L., Mallet, C., Keramidas, M., Lamande, N., Gasc, J. M., DupuisGirod, S., Plauchu, H., Feige, J. J., and Bailly, S. (2008). Bone morphogenetic protein-9 is a circulating vascular quiescence factor. Circ. Res. 102, 914-922.

DeMarini, D. M., Gudi, R., Szkudlinska, A., Rao, M., Recio, L., Kehl, M., Kirby, P. E., Polzin, G., and Richter, P. A. (2008). Genotoxicity of 10 cigarette smoke condensates in four test systems: comparisons between assays and condensates. Mutat. Res. 650(1), 15-29.

Department of Health and Human Services (U.S.). (2004). The Health Consequences of Smoking: A Report of the Surgeon General. DHSS, Centers for Disease Control and Prevention, National Center for Chronic Disease Prevention and Health Promotion, Office on Smoking and Health.

Ding, Y. S., Zhang, L., Jain, R. B., Jain, N., Wang, R. Y., Ashley, D. L., and Watson, C. H. (2008). Levels of tobacco-specific nitrosamines and polycyclic aromatic hydrocarbons in mainstream smoke from different tobacco varieties. Cancer Epidemiol. Biomarkers Prev. 17, 3366-3371.

Djordjevic, M. V., Stellman, S. D., and Zang, E. (2000). Doses of nicotine and lung carcinogens delivered to cigarette smokers. J. Natl. Cancer Inst. 92, $106-111$. 
Fields, W. R., Leonard, R. M., Odom, P. S., Nordskog, B. K., Ogden, M. W., and Doolittle, D. J. (2005). Gene expression in normal human bronchial epithelial (NHBE) cells following in vitro exposure to cigarette smoke condensate. Toxicol. Sci. 86, 84-91.

Fukano, Y., Oishi, M., Chibana, F., Numazawa, S., and Yoshida, T. (2006a). Analysis of the expression of heme oxygenase-1 gene in human alveolar epithelial cells exposed to cigarette smoke condensate. J. Toxicol. Sci. 31, 99-109.

Fukano, Y., Yoshimura, H., and Yoshida, T. (2006b). Heme oxygenase-1 gene expression in human alveolar epithelial cells (A549) following exposure to whole cigarette smoke on a direct in vitro exposure system. Exp. Toxicol. Pathol. 57, 411-418.

Gebel, S., Gerstmayer, B., Bosio, A., Haussmann, H. J., Van, M. E., and Muller, T. (2004). Gene expression profiling in respiratory tissues from rats exposed to mainstream cigarette smoke. Carcinogenesis 25, 169-178.

Harris, J. E. (2001). Smoke yields of tobacco-specific nitrosamines in relation to FTC tar level and cigarette manufacturer: analysis of the Massachusetts Benchmark Study. Public Health Rep. 116, 336-343.

Hoshino, Y., Mio, T., Nagai, S., Miki, H., Ito, I., and Izumi, T. (2001). Cytotoxic effects of cigarette smoke extract on an alveolar type II cellderived cell line. Am. J. Physiol. Lung Cell. Mol. Physiol. 281, L509-L516.

Imai, K., Dalal, S. S., Chen, E. S., Downey, R., Schulman, L. L., Ginsburg, M., and D'Armiento, J. (2001). Human collagenase (matrix metalloproteinase-1) expression in the lungs of patients with emphysema. Am. J. Respir. Crit. Care Med. 163, 786-791.

Kabat, G. C. (2003). Fifty years' experience of reduced-tar cigarettes: what do we know about their health effects? Inhal. Toxicol. 15, 1059-1102.

Lannan, S., Donaldson, K., Brown, D., and MacNee, W. (1994). Effect of cigarette smoke and its condensates on alveolar epithelial cell injury in vitro. Am. J. Physiol. 266(1 Pt 1), L92-L100.

MacNee, W. (2000). Oxidants/antioxidants and COPD. Chest 117(5 Suppl. 1), 303S-317S.

March, T. H., Wilder, J. A., Esparza, D. C., Cossey, P. Y., Blair, L. F., Herrera, L. K., McDonald, J. D., Campen, M. J., Mauderly, J. L., and Seagrave, J. C. (2006). Modulators of cigarette smoke-induced pulmonary emphysema in A/J mice. Toxicol. Sci. 92, 545-559.

Martin, L. A., Byrd, S. K., and Milofsky, R. E. (2003). Rapid communication: effects of tobacco processing on the quantity of benzo[a]pyrene in mainstream smoke. J. Toxicol. Environ Health. A. 66, 1283-1286.

Maunders, H., Patwardhan, S., Phillips, J., Clack, A., and Richter, A. (2007). Human bronchial epithelial cell transcriptome: gene expression changes following acute exposure to whole cigarette smoke in vitro. Am. J. Physiol. Lung Cell. Mol. Physiol. 292, L1248-L1256.

Mercer, B. A., Kolesnikova, N., Sonett, J., and D'Armiento, J. (2004). Extracellular regulated kinase/mitogen activated protein kinase is up- regulated in pulmonary emphysema and mediates matrix metalloproteinase-1 induction by cigarette smoke. J. Biol. Chem. 279, 17690-17696.

Nikula, K. J., March, T. H., Seagrave, J., Finch, G., Barr, E., Menache, M., Hahn, F., and Hobbs, C. (2000). A mouse model of cigarette smoke-induced emphysema. Chest 117(5 Suppl. 1), 246S-247S.

Phillips, J., Kluss, B., Richter, A., and Massey, E. (2005). Exposure of bronchial epithelial cells to whole cigarette smoke: assessment of cellular responses. Altern. Lab. Anim. 33, 239-248.

Rangasamy, T., Misra, V., Zhen, L., Thankersely, C. G., Tuder, R. M., and Biswal, S. (2009). Cigarette smoke-induced emphysema in A/J mice is associated with pulmonary oxidative stress, apoptosis of lung cells, and global alterations in gene expression. Am. J. Physiol. Lung Cell. Mol. Physiol. 296, L888-L900.

Ritter, D., Knebel, J., and Aufderheide, M. (2004). Comparative assessment of toxicities of mainstream smoke from commercial cigarettes. Inhal. Toxicol. 16, 691-700.

Rodgman, A., and Perfetti, T. A. (2008). In The Chemical Components of Tobacco and Tobacco Smoke. CRC Press, Boca Raton, FL.

Seagrave, J. C., Barr, E. B., March, T. H., and Nikula, K. J. (2004). Effects of cigarette smoke exposure and cessation on inflammatory cells and matrix metalloproteinase activity in bronchoalveolar lavage fluid of mice. Exp. Lung Res. 30, 1-15.

Selman, M., Cisneros-Lira, J., Gaxiola, M., Ramirez, R., Kudlacz, E. M., Mitchell, P. G., and Pardo, A. (2003). Matrix metalloproteinases inhibition attenuates tobacco smoke-induced emphysema in Guinea pigs. Chest 123, 1633-1641.

Sen, B., Mahadevan, B., and DeMarini, D. M. (2007). Transcriptional responses to complex mixtures-a review. Mutat. Res. 636, 144-177.

Spira, A., Beane, J., Shah, V., Liu, G., Schembri, F., Yang, X., Palma, J., and Brody, J. S. (2004). Effects of cigarette smoke on the human airway epithelial cell transcriptome. Proc. Natl. Acad. Sci. U.S.A. 101, 10143-10148.

Vulimiri, S. V., Misra, M., Hamm, J. T., Mitchell, M., and Berger, A. (2009). Effects of mainstream cigarette smoke on the global metabolome of human lung epithelial cells. Chem. Res. Toxicol 22, 492-503.

Wardlaw, S. A., Nikula, K. J., Kracko, D. A., Finch, G. L., ThorntonManning, J. R., and Dahl, A. R. (1998). Effect of cigarette smoke on CYP1A1, CYP1A2 and CYP2B1/2 of nasal mucosae in F344 rats. Carcinogenesis 19, 655-662.

Wooten, J. B., Chouchane, S., and McGrath, T. E. (2006). Tobacco smoke constituents affecting oxidative stress. In Cigarette Smoke and Oxidative Stress (B. Halliwell and H. Poulson, Eds.), pp. 6-46. Springer, New York, NY.

Ye, L., Kynaston, H., and Jiang, W. G. (2008). Bone morphogenetic protein-9 induces apoptosis in prostate cancer cells, the role of prostate apoptosis response-4. Mol. Cancer Res. 6, 1594-1606. 